\title{
Sex differences in atheroma burden and endothelial function in patients with early coronary atherosclerosis
}

\section{Seung Hwan Han 1,2, Jang Ho Bae 1,3, David R. Holmes Jr'1, Ryan J. Lennon ${ }^{4}$, Eric Eeckhout ${ }^{5}$, Gregory W. Barsness ${ }^{1}$, Charanjit S. Rihal ${ }^{1}$, and Amir Lerman ${ }^{1 *}$}

${ }^{1}$ Division of Cardiovascular Diseases, Mayo Clinic, 200 First Street SW, Rochester, MN 55905, USA; ${ }^{2}$ Division of Cardiology, Gachon University of Medicine and Science, Incheon, Republic of Korea; ${ }^{3}$ Division of Cardiology, Knoyang University Hospital, Daejeon, Republic of Korea; ${ }^{4}$ Section of Biostatistics, Mayo Clinic, Rochester, MN, USA; and ${ }^{5} 3$ Cardiology Division, Centre Hospitalier Universitaire Vaudois, Lausanne, Switzerland

Received 23 October 2007; revised 19 February 2008; accepted 13 March 2008; online publish-ahead-of-print 18 April 2008

\begin{abstract}
Aims
Women and men have different clinical presentations and outcomes in coronary artery disease (CAD). We tested the hypothesis that sex differences may influence coronary atherosclerotic burden and coronary endothelial function before development of obstructive CAD.

Methods A total of 142 patients (53 men, 89 women; mean \pm SD age, $49.3 \pm 11.7$ years) with early CAD simultaneously and results underwent intravascular ultrasonography and coronary endothelial function assessment. Atheroma burden in the left main and proximal left anterior descending (LAD) arteries was significantly greater in men than women (median, $23.0 \%$ vs. $14.1 \%, P=0.002$; median, $40.1 \%$ vs. $29.3 \%, P=0.001$, respectively). Atheroma eccentricity in the proximal LAD artery was significantly higher in men than women (median, 0.89 vs. $0.80, P=0.04$ ). The length of the coronary segments with endothelial dysfunction was significantly longer in men than women (median, 39.2 vs. $11.1 \mathrm{~mm}, P=0.002$ ). In contrast, maximal coronary flow reserve was significantly lower in women than men $(2.80$ vs. $3.30, P<0.001)$. Sex was an independent predictor of atheroma burden in the left main and proximal LAD arteries (both $P<0.05$ ) by multivariate analysis.

Conclusion Men have greater atheroma burden, more eccentric atheroma, and more diffuse epicardial endothelial dysfunction than women. These results suggest that men have more severe structural and functional abnormalities in epicardial coronary arteries than women, even in patients with early atherosclerosis, which may result in the higher incidence rates of CAD and ST-segment myocardial infarction in men than women.
\end{abstract}

Keywords Atherosclerosis • Endothelium • Sex differences

\section{Introduction}

Coronary artery disease (CAD) is the leading cause of morbidity and mortality in men and women in most developed nations. ${ }^{1}$ Women and men have been shown to have different clinical presentations, prevalence, and clinical outcomes of CAD. ${ }^{2,3}$ Men present more often than women with ST-segment elevation myocardial infarction and have a higher prevalence of CAD adjusted to age. ${ }^{1,4-6}$ Women present more frequently than men, however, for the evaluation of chest pain and are more frequently hospitalized for it. $^{2}$ In addition, women who have CAD, especially younger women, have more adverse outcomes after myocardial infarction and coronary artery bypass grafting surgery than men despite their documented lower angiographic disease burden. ${ }^{7-9}$ These findings indicate that sex may have an important influence on cardiovascular physiology and pathology. ${ }^{10,11}$ Thus, these differences may reflect a differential effect of sex on the pathogenesis of coronary atherosclerosis.

Measurement of atheroma burden by intravascular ultrasonography (IVUS) $)^{12-16}$ and assessment of endothelial function ${ }^{17-20}$ are useful tools for evaluating early features of coronary atherosclerosis. Current study was designed to test the hypothesis that

* Corresponding author. Tel: +1 507255 4152, Fax: +1 507255 2550, Email: lerman.amir@mayo.edu

Published on behalf of the European Society of Cardiology. All rights reserved. (C) The Author 2008. For permissions please email: journals.permissions@oxfordjournals.org. 
sex influences coronary atherosclerotic burden and coronary endothelial function before the development of obstructive CAD. We simultaneously investigated the sex differences in atheroma burden and coronary endothelial function in patients with early coronary atherosclerosis.

\section{Methods}

\section{Study subjects}

All patients had been referred for coronary angiography by an independent cardiologist for evaluation of CAD. From January 2001 to February 2007, patients without obstructive CAD (diameter stenosis, $<30 \%$ by angiography) were prospectively enrolled in tests of endothelial function at Mayo Clinic in Rochester, MN, USA. Exclusion criteria for undergoing testing of endothelial function included presence of myocardial infarction; uncontrolled hypertension; valvular heart disease; cardiomyopathy; ejection fraction $<40 \%$; significant endocrine, hepatic, renal, or inflammatory disease; presentation with acute coronary syndrome; or refusal to participate. The Mayo Clinic Institutional Review Board approved the study, and informed consent was obtained from all participants.

For the current study, a subset of the group undergoing coronary endothelial function testing was selected to also undergo IVUS. Patients who had IVUS were selected randomly and did not sign a separate consent form for the IVUS study. Patients who had previous percutaneous coronary intervention or coronary artery bypass grafting surgery were further excluded for this study. Longacting nitrates or calcium-channel blockers were withheld for $48 \mathrm{~h}$ before the study to allow assessment of baseline coronary physiology. Patients' demographic and laboratory data were obtained from the medical records.

\section{Endothelial function assessment and coronary flow reserve}

Coronary angiography was performed according to standard techniques using the femoral artery approach. Coronary endothelial function was assessed as previously described..$^{21-22}$ Briefly, a Doppler guidewire (0.014" diameter, FloWire; Volcano Corp., Rancho Cordova, CA, USA) within a 2.2-F coronary infusion catheter (Ultrafuse; SciMed Life Systems, Maple Grove, MN, USA) was advanced and positioned in the middle portion of the left anterior descending (LAD) coronary artery. Velocity signals were obtained instantaneously from the Doppler wire by an online fast Fourier transform, and average peak velocity was determined. Intracoronary bolus injections of incremental doses $(18-60 \mu \mathrm{g})$ of adenosine were administered until maximal hyperaemia was achieved, to evaluate endothelium-independent microvascular coronary flow reserve (CFR). CFR was calculated by dividing the average peak velocity after adenosine injection by the average peak velocity at baseline.

Subsequently, to assess endothelium-dependent function, the endothelium-dependent vasodilator acetylcholine was selectively infused into the $L A D$ artery for $3 \mathrm{~min}$ at increasing concentrations $\left(10^{-6}, 10^{-5}\right.$, and $\left.10^{-4} \mathrm{M}\right)$ to obtain effective coronary concentrations of $10^{-8}, 10^{-7}$, and $10^{-6} \mathrm{M}$, respectively. Coronary artery diameter and average peak velocity were measured. After each infusion of acetylcholine, coronary blood flow was calculated from the Doppler-derived time velocity integral and vessel diameter as follows:

$$
\pi \times\left(\frac{\text { coronary artery diameter }}{2}\right)^{2} \times\left(\frac{\text { average peak velocity }}{2}\right) \text {. }
$$

Reproducibility of the measurements from our laboratory is $8 \pm 3 \%$. Percentage diameter change in the mid-LAD artery was measured in the segment $5 \mathrm{~mm}$ distal to the tip of the Doppler wire after each infusion. According to our previous studies, we defined coronary epicardial endothelial dysfunction as $>20 \%$ diameter decrease in response to the maximum dose of acetylcholine compared with the coronary artery diameter measured during baseline angiography in the same artery location. ${ }^{21}$ Total length of endothelial dysfunction was defined as the sum of the lengths of all segments with endothelial dysfunction. Finally, endothelium-independent epicardial coronary artery function was determined by the change in coronary artery diameter in response to intracoronary nitroglycerine bolus injection $(100 \mu \mathrm{g})$.

Coronary artery diameter and length were measured off-line by an independent investigator, who was unaware of the patient's sex and clinical characteristics, by using a quantitative coronary angiography program (Medis Corp., Leiden, The Netherlands) as previously described. ${ }^{23}$ The reproducibility of the measurements from our laboratory is $5 \pm 2 \%$.

\section{Intravascular ultrasonography examination}

After the assessment of coronary endothelial function and CFR, $200 \mu \mathrm{g}$ intracoronary nitroglycerine was given, and IVUS imaging was performed according to previously described methods. ${ }^{23,24}$ A 2.9-F IVUS catheter with electronic scanning (Volcano Corp.) was advanced into the mid-distal LAD artery via a 0.014" guidewire, which was exchanged for a Doppler guidewire, and motorized pullback was performed at a speed of 0.5 to $1.0 \mathrm{~mm} / \mathrm{s}$. The IVUS image was recorded for later off-line analysis. External elastic membrane (EEM) area and lumen area were measured in the proximal, distal, and lesion sites of each left main and proximal LAD artery (from ostium to branching site of first diagonal) by an independent investigator blinded to the clinical data and endothelial function test results.

Atheroma (plaque plus media) area was calculated as EEM area minus lumen area. As previously recommended, ${ }^{25}$ percentage atheroma burden was calculated as: (atheroma area/EEM area) $\times 100$; atheroma eccentricity was calculated as: (maximum - minimum atheroma thickness)/maximum atheroma thickness. The proximal and distal site of each segment was selected as the image slice with the largest atheroma burden within $5 \mathrm{~mm}$ of the proximal and distal ends of each segment. The lesion site selected for analysis was the image slice with the largest percentage atheroma burden in each entire segment. Segments with poor image quality or large vessel diameter exceeding the IVUS scale, very short segments, and severely tortuous vessels were excluded from analysis.

\section{Statistical analysis}

Continuous variables were presented as mean \pm SD for characteristics with appropriately near-symmetrical distributions or as median (interquartile range). Discrete data are presented as frequencies and percentages. Sex comparisons were evaluated with the Student's t-test, the Mann-Whitney U-test, or the Pearson $\chi^{2}$ test. Multiple regression models were used to assess whether the differences between men and women were independent of other risk factors. Log transformations of glucose, triglyceride, and C-reactive protein (CRP) levels were used because of their skewed distributions. Because of the high correlation between body surface area (BSA) and sex $(r=0.46$, $P<0.001$ ), we standardized BSA values for men and women separately, such that the new variable had a mean of 0 and SD of 1 within each sex, and used that variable for modelling. Residual distributions were inspected by normal probability plots; if the plot showed clear deviation from normality, the base 2 log transform was 
applied to the end point and the residuals were inspected again. The length of endothelial dysfunction was skewed because many patients had a length of $0 \mathrm{~mm}$; thus, a multiple regression model for the length of endothelial dysfunction was analysed only in patients with endothelial dysfunction. Covariates for the models were selected by inspecting unadjusted linear associations. Variables significant at the 0.15 level were included in the model as potential confounders. All other hypothesis tests had a 0.05 significance level. All tests were two-sided.

\section{Results}

\section{Patient characteristics and risk factors}

Of the 638 patients who underwent endothelial function testing, 152 patients (23.8\%) were randomly selected to also undergo IVUS during the study period. Ten of these patients were excluded on the basis of previous percutaneous coronary intervention; therefore, the cohort comprised 142 patients [ 53 men (37\%), 89 women $(63 \%)]$ who had a mean \pm SD age of $49.3 \pm 11.7$ years. The clinical characteristics of the patients are shown in Table 1. Fifty-four women (61\%) were postmenopausal, 20 of whom (37\%) were receiving hormone-replacement therapy before the present study. Men were significantly younger than women $(45.2 \pm 11.0$ vs. $51.7 \pm 11.5$ years, $P=0.001)$ and had lower high- density lipoprotein cholesterol levels $(41.48 \pm 10.33$ vs. $57.98 \pm$ $16.41 \mathrm{mg} / \mathrm{dL}, P<0.001)$. Women had significantly larger body mass index $\left(30.14 \pm 6.78\right.$ vs. $\left.28.23 \pm 4.42 \mathrm{~kg} / \mathrm{m}^{2}, \quad P=0.04\right)$, higher total cholesterol ( $190.44 \pm 37.57$ vs. $175.28 \pm 36.48 \mathrm{mg} /$ $\mathrm{dL}, P=0.02)$ and CRP values $[0.36(0.14-0.90)$ vs. $0.16(0.07-$ $0.40) \mathrm{mg} / \mathrm{dL}, P=0.01]$, and lower haemoglobin $(12.96 \pm 1.11 \mathrm{vs}$. $13.98 \pm .04 \mathrm{~g} / \mathrm{dL}, \quad P<0.001)$ and creatinine $(0.91 \pm 0.13$ vs. $1.10 \pm 0.21, P<0.001)$ values. Other parameters shown in Table 1 were not significantly different between men and women.

\section{Intravascular ultrasonography findings}

Some segments were excluded because of poor image quality (17 segments in the left main and three segments in the LAD arteries), large vessel diameter exceeding the IVUS scale (18 segments in the left main), very short segments (10 segments in the left main), or severely tortuous vessels (three segments in the LAD). A total of 97 IVUS findings in the left main artery (from 36 men and 61 women) and 136 IVUS findings in the proximal LAD artery (from 48 men and 88 women) remained for analysis. The EEM area, lumen area, and atheroma area of the lesion site in the left main artery were significantly larger in men (all $P<0.05$; Table 2). Men also had significantly greater atheroma burden in the proximal site, distal site, and lesion site of the left main artery (all $P<0.05$; Table 2, Figure $1 A$ ). In the proximal LAD

\section{Table I Patient characteristics ${ }^{\mathrm{a}}$}

\begin{tabular}{|c|c|c|c|}
\hline \multirow[t]{2}{*}{ Characteristic } & \multicolumn{2}{|l|}{ Patients } & \multirow[t]{2}{*}{$P$-value } \\
\hline & Men $(n=53)$ & Women $(n=89)$ & \\
\hline Age (year) & $45.2 \pm 11.0$ & $51.7 \pm 11.5$ & 0.001 \\
\hline Hypertension & $30(56.6)$ & $44(49.4)$ & 0.41 \\
\hline Diabetes mellitus & $3(5.7)$ & $10(11.2)$ & 0.27 \\
\hline Hyperlipidemia & $32(60.4)$ & $54(60.7)$ & 0.74 \\
\hline Current smoking & $8(15.1)$ & $10(11.2)$ & 0.20 \\
\hline Body mass index $\left(\mathrm{kg} / \mathrm{m}^{2}\right)$ & $28.23 \pm 4.42$ & $30.14 \pm 6.78$ & 0.04 \\
\hline Mean arterial pressure $(\mathrm{mmHg})$ & $96.56 \pm 14.00$ & $99.29 \pm 15.23$ & 0.31 \\
\hline Ejection fraction (\%) & $65.18 \pm 4.28$ & $64.10 \pm 5.62$ & 0.24 \\
\hline Creatinine $(\mathrm{mg} / \mathrm{dL})$ & $1.10 \pm 0.21$ & $0.91 \pm 0.13$ & $<0.001$ \\
\hline Haemoglobin (g/dL) & $13.98 \pm 1.04$ & $12.96 \pm 1.11$ & $<0.001$ \\
\hline Glucose (mg/dL) & $94(89-101)$ & $94(86-104)$ & 0.56 \\
\hline Total cholesterol (mg/dL) & $175.28 \pm 36.48$ & $190.44 \pm 37.57$ & 0.02 \\
\hline LDL cholesterol (mg/dL) & $106.73 \pm 32.08$ & $109.09 \pm 33.10$ & 0.68 \\
\hline HDL cholesterol (mg/dL) & $41.48 \pm 10.33$ & $57.98 \pm 16.41$ & $<0.001$ \\
\hline Triglycerides (mg/dL) & $129(86-166)$ & $98(64-147)$ & 0.05 \\
\hline C-reactive protein (mg/dL) & $0.16(0.07-0.40)$ & $0.36(0.14-0.90)$ & 0.01 \\
\hline \multicolumn{4}{|l|}{ Medications } \\
\hline Aspirin & $31(58.5)$ & $45(50.6)$ & 0.36 \\
\hline$\beta$-Blockers & $17(32.1)$ & $28(31.5)$ & 0.94 \\
\hline ACE inhibitors & $13(24.5)$ & $17(19.1)$ & 0.44 \\
\hline Calcium-channel antagonists & $20(37.7)$ & $35(39.3)$ & 0.85 \\
\hline Lipid-lowering agents & $23(43.4)$ & $35(39.3)$ & 0.63 \\
\hline
\end{tabular}

ACE, angiotensin-converting enzyme; HDL, high-density lipoprotein; LDL, low-density lipoprotein. ${ }^{a} V$ alues are no. of patients (\%), mean $\pm \mathrm{SD}$, or median (interquartile range). 
Table 2 Intravascular ultrasonography findings in the left main and proximal left anterior descending arteries ${ }^{\mathbf{a}}$

\begin{tabular}{|c|c|c|c|c|c|c|}
\hline \multirow[t]{2}{*}{ Location } & \multicolumn{2}{|l|}{ Left main artery } & \multirow[t]{2}{*}{$P$-value } & \multicolumn{2}{|c|}{ Proximal LAD artery } & \multirow[t]{2}{*}{$P$-value } \\
\hline & Men $(n=36)$ & Women $(n=61)$ & & Men $(n=48)$ & Women $(n=88)$ & \\
\hline \multicolumn{7}{|l|}{ Proximal } \\
\hline EEM area $\left(\mathrm{mm}^{2}\right)$ & $24.2(19.6-26.6)$ & $19.7(17.2-22.3)$ & $<0.001$ & $18.4(16.2-20.2)$ & $15.0(12.9-16.8)$ & $<0.001$ \\
\hline Lumen area $\left(\mathrm{mm}^{2}\right)$ & $19.7(15.5-23.2)$ & $17.7(15.8-19.6)$ & 0.06 & $13.5(11.7-15.4)$ & $12.4(10.0-14.2)$ & 0.01 \\
\hline Atheroma area $\left(\mathrm{mm}^{2}\right)$ & $3.2(1.8-5.0)$ & $1.6(1.1-2.9)$ & 0.002 & $4.3(2.1-6.0)$ & $2.2(1.1-3.6)$ & $<0.001$ \\
\hline Atheroma burden (\%) & $14.5(8.4-20.5)$ & $8.8(5.6-14.8)$ & 0.01 & $22.0(11.8-34.3)$ & $15.2(8.1-23.9)$ & 0.007 \\
\hline \multicolumn{7}{|l|}{ Distal } \\
\hline EEM area $\left(\mathrm{mm}^{2}\right)$ & $25.4(21.2-27.5)$ & $19.7(18.0-21.9)$ & $<0.001$ & $16.8(14.5-21.8)$ & $15.3(13.6-17.6)$ & 0.01 \\
\hline Lumen area $\left(\mathrm{mm}^{2}\right)$ & $18.8(16.9-22.0)$ & $17.6(15.8-19.0)$ & 0.006 & $12.9(10.3-16.1)$ & $12.0(10.0-14.4)$ & 0.17 \\
\hline Atheroma area $\left(\mathrm{mm}^{2}\right)$ & $5.2(1.9-8.3)$ & $1.8(1.2-3.7)$ & 0.002 & $2.7(1.4-7.5)$ & $2.2(1.3-4.6)$ & 0.21 \\
\hline Atheroma burden (\%) & $19.4(8.3-32.1)$ & $9.4(6.0-18.8)$ & 0.02 & $18.4(7.7-36.4)$ & $17.9(7.8-29.4)$ & 0.56 \\
\hline \multicolumn{7}{|l|}{ Lesion } \\
\hline EEM area $\left(\mathrm{mm}^{2}\right)$ & $24.2(20.0-27.1)$ & $19.7(17.4-22.1)$ & $<0.001$ & $17.1(15.4-21.2)$ & $15.1(13.2-16.7)$ & $<0.001$ \\
\hline Lumen area $\left(\mathrm{mm}^{2}\right)$ & $18.3(15.4-21.0)$ & $16.7(14.7-18.5)$ & 0.03 & $10.3(8.7-12.2)$ & $10.4(8.3-12.3)$ & 0.63 \\
\hline Atheroma area $\left(\mathrm{mm}^{2}\right)$ & $5.8(3.2-7.7)$ & $2.8(1.4-4.2)$ & $<0.001$ & $7.3(4.8-8.7)$ & $4.3(2.3-6.2)$ & $<0.001$ \\
\hline Atheroma burden (\%) & $23.0(14.3-32.4)$ & $14.1(8.1-21.8)$ & 0.002 & $40.1(30.3-49.7)$ & $29.3(18.2-42.4)$ & 0.001 \\
\hline Atheroma eccentricity & $0.91(0.81-0.97)$ & $0.90(0.67-0.97)$ & 0.24 & $0.89(0.78-0.94)$ & $0.80(0.70-0.93)$ & 0.04 \\
\hline
\end{tabular}

EEM, external elastic membrane; LAD, left anterior descending artery.

${ }^{a}$ Values are median (interquartile range).

artery, the EEM area and atheroma area of the lesion site were significantly larger in men (both $P<0.001$; Table 2). Men also had significantly greater atheroma burden in the proximal site and lesion site of the proximal LAD artery than women (both $P<0.01$; Table 2, Figure $1 A$ ). Atheroma eccentricity in the lesion site of the proximal LAD artery was also significantly greater in men than in women $[0.89(0.78-0.94)$ vs. $0.80(0.70-0.93), P=0.04$; Table 2, Figure 1B].

\section{Coronary endothelial function assessment}

After intracoronary infusion of acetylcholine, the percentage change in mid-LAD artery diameter was similar between men and women (Table 3). However, the total length of coronary segments with endothelial dysfunction was significantly longer in men than in women $[39.2(0.0-71.6)$ vs. $11.1(0.0-38.5) \mathrm{mm}$, $P=0.002$; Table 3, Figure 2]. Even after correction for BSA, men had significantly longer coronary artery segments with endothelial dysfunction than women $[17.9(0.0-35.6)$ vs. $6.8(0.0-22.6) \mathrm{mm} /$ $\mathrm{m}^{2}, P=0.008$; Table 3]. The percentage change in artery diameter after intracoronary nitroglycerine infusion was not significantly different by sex (Table 3).

\section{Coronary microvascular function test}

Microvascular endothelial-dependent function, assessed by percentage change in coronary blood flow after intracoronary acetylcholine infusion, was not significantly different by sex (Table 3). In contrast, endothelium-independent microvascular function, assessed by maximal CFR after intracoronary adenosine infusion, was significantly lower in women than in men (Table 3, Figure 3).

\section{Independent predictors of atheroma burden in left main and proximal left anterior descending arteries}

By univariate analysis, male sex, age, mean arterial pressure (per $10 \mathrm{mmHg}$ ), creatinine level (per $0.2 \mathrm{mg} / \mathrm{dL}$ ), haemoglobin value, and $\log _{2}$ triglyceride level were predictors of $\log _{2}$ atheroma burden in the left main artery. Male sex, age, haemoglobin value, and $\log _{2}$ triglyceride level were predictors of atheroma burden in the proximal LAD artery by univariate analysis (Table 4). By multivariate analysis, male sex was an independent predictor of $\log _{2}$ atheroma burden in the left main artery $\{\beta$-coefficient $[95 \%$ confidence interval $(\mathrm{Cl})], 0.50(0.03-0.97), P=0.04\}$ and atheroma burden in the proximal LAD artery [8.91 (2.52-15.30), $P=0.007]$ (Table 5).

\section{Independent predictors of length of endothelial dysfunction and coronary flow reserve}

Because the length of artery with endothelial dysfunction was $0 \mathrm{~mm}$ in 53 patients (37\%), the multiple regression model for the length of endothelial dysfunction was performed including only patients with endothelial dysfunction $(n=89)$. Male sex and age were predictors of the length of the coronary segment with endothelial dysfunction by univariate analysis (Table 4). By multivariate analysis, male sex almost reached statistical significance as a predictor of the length of endothelial dysfunction $[\beta$-coefficient 


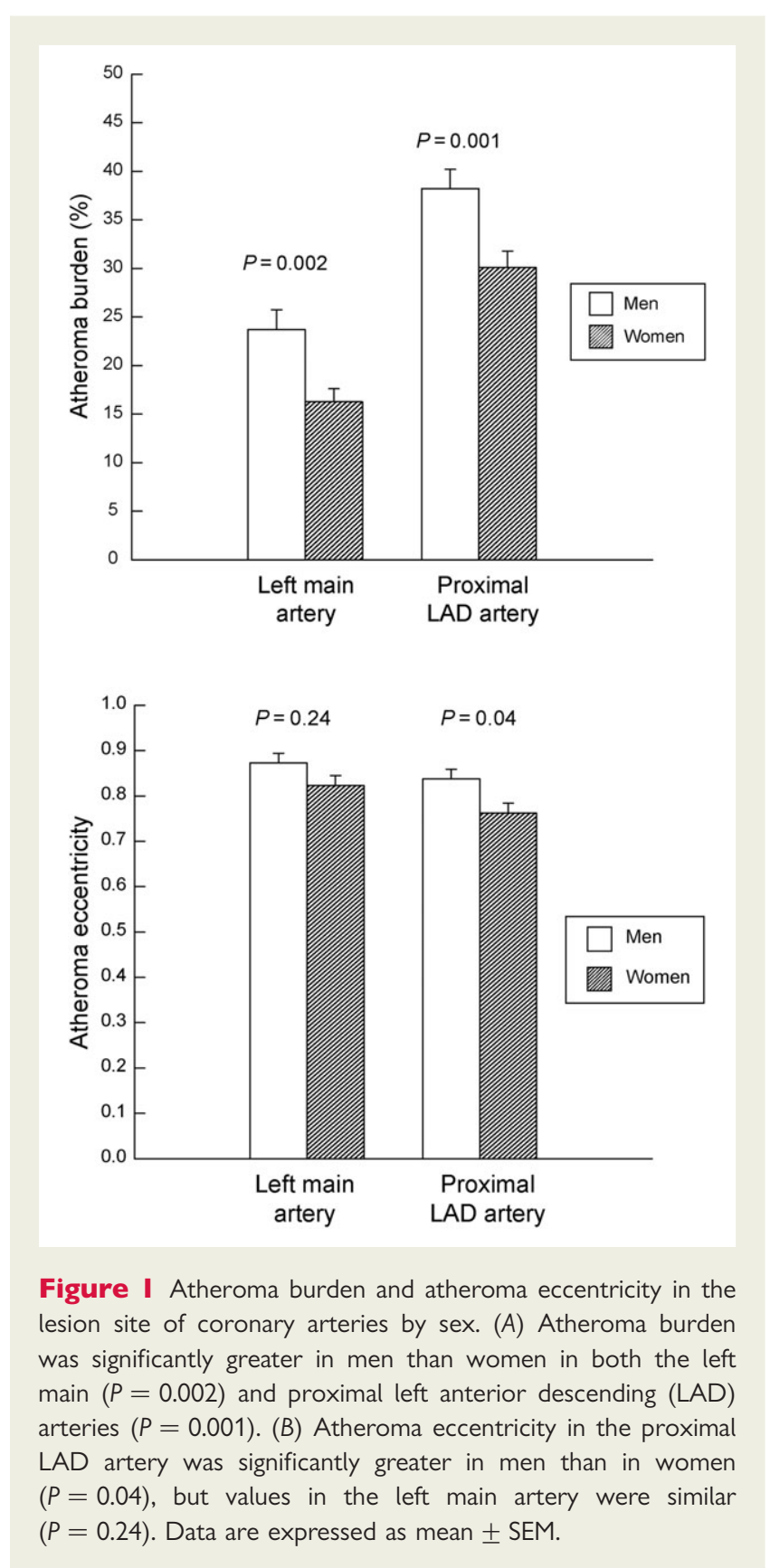

(95\% Cl), 11.94 ( -0.45 to 24.33), $P=0.059$; Table 5]. Male sex, age, sex-standardized BSA, and creatinine (per $0.2 \mathrm{mg} / \mathrm{dL}$ ), haemoglobin, $\log _{2}$ glucose, and $\log _{2}$ CRP values were predictors of $\log _{2}$ maximal CFR by univariate analysis (Table 4$)$. Age $(P=0.047)$, sex-standardized BSA $(P=0.002)$, $\log _{2}$ glucose concentration $(P=0.04)$, and $\log _{2}$ CRP value $(P=0.049)$ were independent predictors of $\log _{2}$ maximal CFR by multivariate analysis (Table 5).

\section{Discussion}

To our knowledge, this is the first study to simultaneously investigate atheroma burden, endothelial function, and microvascular function by sex in patients with early coronary atherosclerosis. Our study showed that men with early atherosclerosis had more severe atheroma burden, more eccentric atheroma, and more diffuse epicardial artery endothelial dysfunction than women. The current study supports a potential mechanism for the differential incidence and clinical presentations of CAD between men and women.

Age-adjusted CAD incidence rate and sudden cardiac death rate in men exceed those in women., ${ }^{1,5,26}$ In addition, men present more often than women with ST-segment elevation myocardial infarction. ${ }^{27,28}$ Women more frequently present with non-obstructive coronary arteries and non-Q-wave myocardial infarctions. In addition, aggressive revascularization management strategies have not been found to be effective in women, although they have a clear benefit in men. ${ }^{3,29-31}$ However, the potential mechanism for these differences in the clinical presentation of CAD is not known.

Recent clinical studies indicated that the level of plaque and plaque progression as measured by IVUS appeared to be related to future cardiovascular events, ${ }^{12-15}$ and IVUS-measured changes in atheroma burden was suggested as a surrogate cardiovascular end point. ${ }^{16}$ Our IVUS findings were similar to coronary angiographic findings in previous reports, which showed that women had lower rates of obstructive CAD at angiography when evaluated for symptoms suggestive of myocardial ischaemia. ${ }^{2}$ Recently, Nicholls et $a .^{32}$ reported that the atheroma volume in women with angiographic CAD is less than in men, despite the presence of more cardiovascular risk factors in women. Our study extends this previous observation and demonstrates that the difference in atheroma burden exists even at early stages of disease. Moreover, the women in the current study had more CAD risk factors in terms of age, body mass index, total cholesterol level, haemoglobin value, and CRP levels. Even accounting for different cardiovascular risk factors between sexes, male sex was an independent predictor of atheroma burden in left main and proximal LAD arteries by multivariate analysis. In addition, our study demonstrated that the morphology of atheroma was more eccentric in men than in women. Thus, our study shows that in patients with early $C A D$, men have greater atheroma burden and eccentric atheroma in coronary arteries than do women.

These findings may have clinical implications. Virmani et al. ${ }^{33}$ previously reported that plaque rupture in patients with sudden coronary death was more frequent in men and that plaque erosion was more frequently found in young women. Our IVUS findings that men with early atherosclerosis had more severe atheroma burden and eccentric atheroma in coronary arteries suggest that these characteristics may contribute to a higher rate of plaque rupture.

Similar to anatomic findings such as atheroma burden measured by IVUS, functional measurements such as endothelium-dependent vasomotor function of the coronary and brachial arteries have been shown to predict long-term cardiovascular risk, including cardiac and cerebrovascular events. ${ }^{17-20}$ In previous human studies, women had significantly improved flow-mediated dilator response to hyperaemia as measured by high-resolution ultrasonography of the brachial artery. ${ }^{34,35}$ Our study showed that men had significantly longer coronary segments with endothelial dysfunction. Thus, to our knowledge, this is the first study to show that 
Table 3 Coronary epicardial and microvascular function ${ }^{a}$

\begin{tabular}{|c|c|c|c|}
\hline Measurement & Men $(n=53)$ & Women $(n=89)$ & $P$-value \\
\hline \multicolumn{4}{|l|}{ Epicardial endothelial-dependent function } \\
\hline Percentage change in mid-LAD diameter after acetylcholine IC & $-10.6(-26.0$ to -1.3$)$ & $-10.1(-22.4-0.4)$ & 0.41 \\
\hline Length of the endothelial dysfunction (mm) & $39.2(0.0-71.6)$ & $11.1(0.0-38.5)$ & 0.002 \\
\hline Length of endothelial dysfunction/BSA $\left(\mathrm{mm} / \mathrm{m}^{2}\right)$ & $17.9(0.0-35.6)$ & $6.8(0.0-22.6)$ & 0.008 \\
\hline \multicolumn{4}{|l|}{ Epicardial endothelial-independent function } \\
\hline Percentage change in mid-LAD diameter after nitroglycerine IC & $9.3(2.5-20.4)$ & $10.0(0.0-18.7)$ & 0.74 \\
\hline \multicolumn{4}{|l|}{ Microvascular endothelial-dependent function } \\
\hline Percentage change in CBF after acetylcholine IC & $27.3(-22.5-98.7)$ & $36.1(-9.8-82.7)$ & 0.89 \\
\hline \multicolumn{4}{|l|}{ Microvascular endothelial-independent function } \\
\hline Maximal CFR after adenosine IC & $3.30(2.90-4.00)$ & $2.80(2.40-3.20)$ & $<0.001$ \\
\hline
\end{tabular}

$B S A$, body surface area; CBF, coronary blood flow; CFR, coronary flow reserve; IC, intracoronary infusion. $L A D$, left anterior descending artery.

${ }^{a}$ Values are median (interquartile range).

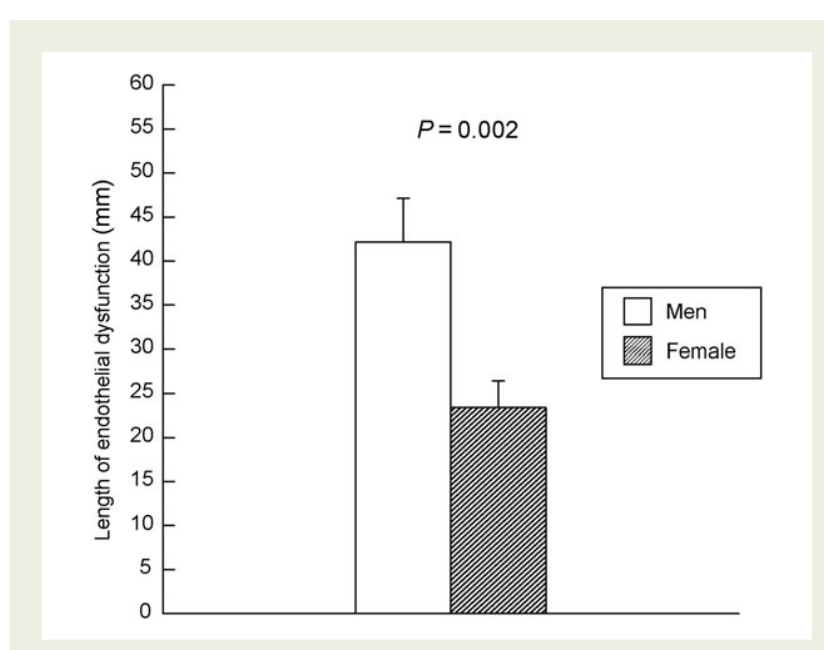

Figure 2 Graph shows the length of the coronary segments with epicardial endothelial dysfunction after intracoronary acetylcholine infusion. The segments were significantly longer in men than women $(P=0.002)$. Data are expressed as mean \pm SEM.

men have more segments with vascular injury and abnormal repair, which are at risk for the development of atherosclerosis and future cardiovascular events.

Taken together, our IVUS findings and results of functional studies show that men have more severe structural and functional abnormalities than women in epicardial coronary arteries. These abnormalities may explain the higher prevalence of CAD and the higher incidences of ST-segment elevation myocardial infarction and sudden cardiac death due to plaque rupture in men.

Although sex was not an independent predictor of maximal CFR by multivariate analysis, our study showed that women had significantly lower maximal CFR than men. These results are consistent with those of a previous report that showed women had slightly lower coronary vasodilatory reserve even with normal coronary angiographic results. ${ }^{36}$ The endothelial-independent microvascular

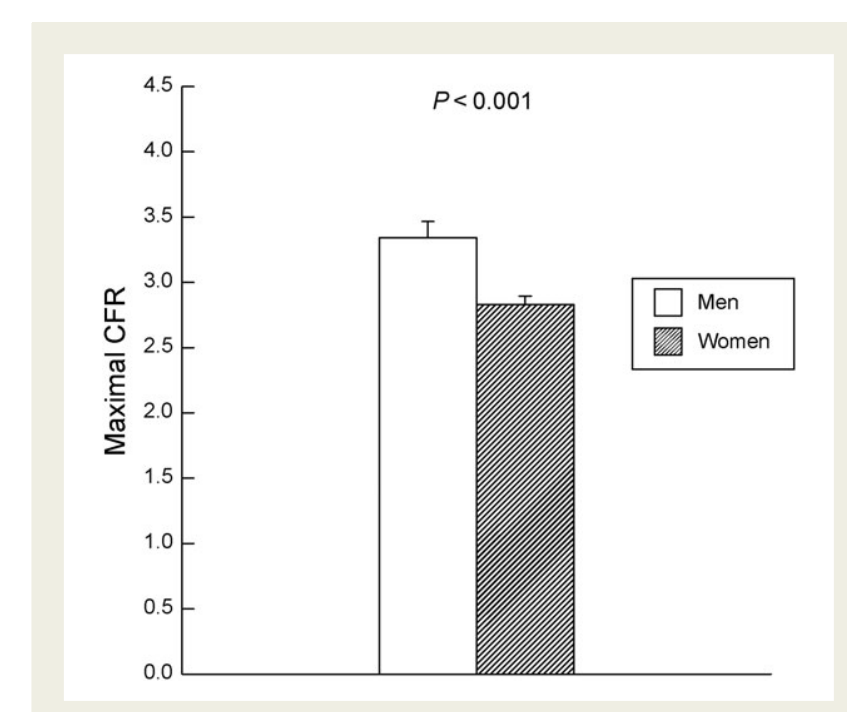

Figure 3 Maximal coronary flow reserve (CFR) after intracoronary infusion of adenosine was significantly decreased in women compared with men $(P<0.001)$. Data are expressed as mean \pm SEM.

dysfunction was an independent predictor of adverse outcomes in patients with mild CAD. ${ }^{37} \mathrm{~A}$ recent clinical study reported that coronary microvascular dysfunction was not associated with markers of inflammatory or endothelial cell activation in women with chest pain in the absence of obstructive CAD. ${ }^{38}$ This result is consistent with our current findings regarding the disparity between epicardial endothelial function and microvascular endothelial-independent function in women. ${ }^{38}$ It has been suggested that the mechanism of myocardial ischaemia in women may be localized to the microvascular coronary arteries and that abnormal microvascular function may have prognostic implications. ${ }^{38-42}$ Our microvascular function results support these observations. 
Table 4 Predictors of atheroma burden in left main and proximal left anterior descending arteries, epicardial function, and microvascular function by univariate analysis $^{\mathbf{a}}$

\begin{tabular}{|c|c|c|c|c|c|c|c|c|}
\hline \multirow[t]{2}{*}{ Parameter } & \multicolumn{2}{|c|}{$\begin{array}{l}\log _{2} \text { atheroma burden in left } \\
\text { main }\end{array}$} & \multicolumn{2}{|c|}{$\begin{array}{l}\text { Atheroma burden in proximal } \\
\text { LAD }\end{array}$} & \multicolumn{2}{|c|}{$\begin{array}{l}\text { Length of coronary segments } \\
\text { with endothelial dysfunction }\end{array}$} & \multicolumn{2}{|l|}{$\log _{2}$ maximal CFR } \\
\hline & $\beta(95 \% \mathrm{Cl})$ & $P$ & $\beta(95 \% \mathrm{Cl})$ & $P$ & $\beta(95 \% \mathrm{Cl})$ & $P$ & $\beta(95 \% \mathrm{Cl})$ & $P$ \\
\hline Male sex & $0.62(0.23-1.01)$ & 0.002 & $8.12(2.80-13.44)$ & 0.003 & $15.59(3.76-27.42)$ & 0.01 & $0.22(0.10-0.34)$ & $<0.001$ \\
\hline Age (per year) & $0.02(0.001-0.04)$ & 0.04 & $0.29(0.07-0.52)$ & 0.01 & $-0.61(-1.14$ to -0.08$)$ & 0.02 & $-0.01(-0.01-0.003)$ & 0.001 \\
\hline Diabetes mellitus & $-0.46(-1.18-0.26)$ & 0.21 & $5.49(-3.40-14.37)$ & 0.22 & $-15.18(-34.03-3.86)$ & 0.12 & $0.01(-0.20-0.23)$ & 0.91 \\
\hline Current smoking & $-0.19(-0.76-0.37)$ & 0.50 & $1.07(-6.88-9.00)$ & 0.79 & $-1.74(-19.59-16.11)$ & 0.85 & $-0.04(-0.23-0.15)$ & 0.68 \\
\hline BSA (per $0.25 \mathrm{~m}^{2}$ ) & $0.25(0.04-0.47)$ & 0.02 & $1.99(-0.81-4.78)$ & 0.16 & $4.21(-2.94-10.81)$ & 0.21 & $0.12(0.06-0.19)$ & $<0.001$ \\
\hline Sex-standardized BSA & $0.10(-0.11-0.31)$ & 0.34 & $0.09(-2.57-2.76)$ & 0.95 & $0.22(-6.01-6.45)$ & 0.95 & $0.08(0.02-0.14)$ & 0.01 \\
\hline BMI (per 5 kg/m²) & $0.09(-0.07-0.25)$ & 0.26 & $-0.15(-2.29-1.99)$ & 0.89 & $-2.10(-7.21-3.02)$ & 0.42 & $0.01(-0.05-0.06)$ & 0.85 \\
\hline MAP (per 10 mmHg) & $0.18(0.04-0.32)$ & 0.01 & $0.19(-1.61-2.00)$ & 0.83 & $-3.38(-7.41-0.65)$ & 0.10 & $-0.04(-0.08-0.01)$ & 0.09 \\
\hline Creatinine (per 0.2 mg/dL) & $0.28(0.09-0.48)$ & 0.005 & $2.50(-0.29-5.28)$ & 0.08 & $1.26(-4.67-7.20)$ & 0.67 & $0.07(0.01-0.14)$ & 0.03 \\
\hline Haemoglobin & $0.32(0.16-0.48)$ & $<0.001$ & $3.25(1.09-5.41)$ & 0.004 & $1.13(-4.26-6.52)$ & 0.68 & $0.06(0.01-0.12)$ & 0.02 \\
\hline $\log _{2}$ glucose & $0.12(-0.51-0.76)$ & 0.70 & $7.76(-0.85-16.36)$ & 0.08 & $-17.23(-35.79-1.33)$ & 0.07 & $-0.22(-0.43$ to -0.02$)$ & 0.03 \\
\hline Total cholesterol (per 40 mg/dL) & $-0.01(-0.22-0.21)$ & 0.96 & $-0.10(-2.89-2.69)$ & 0.94 & $0.17(-6.17-6.51)$ & 0.96 & $-0.01(-0.08-0.06)$ & 0.80 \\
\hline LDL cholesterol (per 25 mg/dL) & $-0.01(-0.17-0.14)$ & 0.87 & $-0.27(-2.29-1.76)$ & 0.80 & $0.71(-3.90-5.32)$ & 0.76 & $0.01(-0.04-0.05)$ & 0.83 \\
\hline HDL cholesterol (per 10 mg/dL) & $-0.08(-0.20-0.04)$ & 0.20 & $-0.62(-2.22-0.99)$ & 0.45 & $-1.85(-5.81-2.11)$ & 0.36 & $-0.02(-0.06-0.01)$ & 0.22 \\
\hline $\log _{2}$ triglyceride & $0.28(0.02-0.53)$ & 0.03 & $3.25(0.19-6.30)$ & 0.04 & $1.40(-5.95-8.75)$ & 0.71 & $0.01(-0.06-0.09)$ & 0.76 \\
\hline $\log _{2} \mathrm{CRP}$ & $0.03(-0.06-0.13)$ & 0.48 & $0.77(-0.51-2.04)$ & 0.24 & $-0.51(-3.43-2.42)$ & 0.73 & $-0.03(-0.06$ to -0.004$)$ & 0.02 \\
\hline
\end{tabular}

BMI, body mass index; BSA, body surface area; CFR, coronary flow reserve; HDL, high-density lipoprotein; LAD, left anterior descending artery; LDL, low-density lipoprotein; MAP, mean arterial pressure.

avalues are $\beta$-coefficient [95\% confidence interval (Cl)]. 
Table 5 Independent predictors of epicardial and microvascular function and atheroma burden in the left main and proximal left anterior descending arteries by multivariable analysis ${ }^{\mathrm{a}}$

\begin{tabular}{|c|c|c|c|c|c|c|c|c|}
\hline \multirow[t]{2}{*}{ Parameter } & \multicolumn{2}{|c|}{$\begin{array}{l}\log _{2} \text { atheroma burden in } \\
\text { left main artery }\end{array}$} & \multicolumn{2}{|c|}{$\begin{array}{l}\text { Atheroma burden in proximal } \\
\text { LAD }\end{array}$} & \multicolumn{2}{|c|}{$\begin{array}{l}\text { Length of coronary segments } \\
\text { with endothelial dysfunction }\end{array}$} & \multicolumn{2}{|l|}{$\log _{2}$ maximal CFR } \\
\hline & $\beta(95 \% \mathrm{Cl})$ & $\mathbf{P}$ & $\beta(95 \% \mathrm{Cl})$ & $P$ & $\beta(95 \% \mathrm{Cl})$ & $P$ & $\beta(95 \% \mathrm{Cl})$ & $P$ \\
\hline Male sex & $0.50(0.03-0.97)$ & 0.04 & $8.91(2.52-15.3)$ & 0.007 & $11.9(-0.45-24.3)$ & 0.059 & $0.11(-0.04-0.26)$ & 0.13 \\
\hline Age (per year) & $0.02(0.003-0.04)$ & 0.02 & $0.38(0.15-0.60)$ & 0.001 & $-0.28(-0.87-0.31)$ & 0.34 & $-0.005(-0.011$ to -0.00007$)$ & 0.047 \\
\hline MAP (per $10 \mathrm{mmHg}$ ) & $0.14(0.01-0.27)$ & 0.03 & & & $-1.50(-5.70-2.71)$ & 0.48 & $-0.01(-0.05-0.03)$ & 0.59 \\
\hline Creatinine (per $0.2 \mathrm{mg} / \mathrm{dL}$ ) & $0.03(-0.19-0.25)$ & 0.78 & $-0.70(-3.74-2.34)$ & 0.65 & & & $0.02(-0.05-0.10)$ & 0.67 \\
\hline Haemoglobin & $0.19(0.02-0.36)$ & 0.03 & $1.99(-0.31-4.30)$ & 0.09 & & & $0.006(-0.05-0.06)$ & 0.84 \\
\hline $\log _{2}$ triglycerides & $0.16(-0.08-0.39)$ & 0.19 & $1.79(-1.14-4.72)$ & 0.23 & & & & \\
\hline Uric acid & $0.01(-0.11-0.13)$ & 0.84 & & & & & $0.01(-0.03-0.05)$ & 0.59 \\
\hline $\log _{2}$ glucose & & & $5.43(-2.78-13.6)$ & 0.19 & $-8.91(-29.9-12.2)$ & 0.40 & $-0.21(-0.41$ to -0.01$)$ & 0.04 \\
\hline Diabetes mellitus & & & & & $-6.11(-27.2-15.0)$ & 0.57 & & \\
\hline Sex-standardized BSA & & & & & & & $0.10(0.04-0.16)$ & 0.002 \\
\hline $\log _{2}$ CRP & & & & & & & $-0.03(-0.06$ to -0.0002$)$ & 0.049 \\
\hline
\end{tabular}

BSA, body surface area; CFR, coronary flow reserve; CRP, C-reactive protein; LAD, left anterior descending artery; MAP, mean arterial pressure.

${ }^{a}$ Values are $\beta$-coefficient [95\% confidence interval (CI)]. 
Older age was an independent predictor of atheroma burden in the left main and proximal LAD arteries and of maximal CFR in our study. In this study, women were on an average 6.5 years older than men. Our results suggest that if we had enrolled more older men, sex differences in these parameters might be more clearly demonstrated.

The primary reason for the low incidence of $C A D$ in premenopausal women compared with age-matched men may be related to the preventive effects of oestrogen, as was documented in animal studies of the antiatherosclerotic, antioxidative, and antiinflammatory effects of oestrogen. ${ }^{4-45}$ One previous animal study $^{46}$ reported that basal release of nitric oxide from endothelium-intact aortic rings was greater in female rabbits than in male rabbits and was related to circulating oestradiol concentrations. Oestrogen administration in humans has been shown to enhance acetylcholine-stimulated increases in coronary blood flow. $^{47}$ In addition, oestrogen decreases cellular hypertrophy, smooth muscle cell migration, and lower collagen deposition in response to injury, which may lead to thinner fibrous plaque in women. ${ }^{48}$ In our study, we did not find significant differences in coronary atheroma burden, endothelial function, or microvascular function between premenopausal women and postmenopausal women (data not shown). In addition, there were no significant differences in these parameters in postmenopausal women regardless of whether they were receiving oestrogen-replacement therapy (ERT, $n=20)$ or not $(n=34)$. Variable postmenopausal period, duration of ERT, and different starting ages of ERT after menopause may affect our results. Therefore, our study further suggests that the effects of long-term ERT on coronary atheroma burden, endothelial function, and microvascular function in postmenopausal women should be clarified in future large-scale clinical studies.

Androgens have been shown to affect the expression of atherosclerosis-related genes in men but not in women, perhaps contributing to the sex-related differences in CAD prevalence. ${ }^{49}$ The variations in plasma sex hormones and receptor genes, acting with endothelial and vascular smooth muscle factors, may be potential links to the sex differences in vascular structure and function in ischaemic heart disease. Sex differences in CAD also may be caused by non-hormonal factors. ${ }^{50}$

The current study has several limitations. It is possible that the extent of atheroma throughout the coronary tree is not uniform and that the extent of plaque demonstrated in one cross-section does not reflect the patient's plaque burden in general. However, men in our study had greater atheroma burden than women in several different sites, such as the proximal, distal, and lesion sites of the left main artery and the proximal and lesion sites of the proximal LAD artery.

We also cannot exclude the possibility of referral bias. Since the main goal of the study was to detect differences in atheroma, endothelial function, and microvascular function between sexes, however, we believe that the selection bias is minimal. Regarding a sex-based referral bias for coronary angiography, more recent studies have shown less of a sex-related difference in referral patterns for coronary angiography than earlier studies. ${ }^{51-53}$ Another limitation was the possibility of enrolling patients who had shown near-normal results of coronary angiography. However, the segments that were near normal by coronary angiography usually had some degree of atheroma by the IVUS study. Therefore, IVUS rather than coronary angiography may provide more detailed information on the characteristics of atherosclerosis by sex. In this study, we investigated only LAD territory, since it is the largest artery and easier from a technical and risk standpoint; further study in the left circumflex and right coronary arteries will be warranted in the future. The analysis of several end points in this paper increases the chance (above the nominal rate of 5\%) that some significant results reflect spurious associations.

In conclusion, the present study demonstrated that in early atherosclerosis, men have greater atheroma burden, more eccentric atheroma, and more diffuse epicardial endothelial dysfunction than women. These results suggest that men have more severe structural and functional abnormalities in epicardial coronary arteries than women, even in patients with early atherosclerosis. These factors may influence the higher incidence rates of CAD and ST-segment myocardial infarction in men than women.

Conflict of interest: none declared.

\section{References}

1. Rosamond W, Flegal K, Friday G, Furie K, Go A, Greenlund K, Haase N, Ho M, Howard V, Kissela B, Kittner S, Lloyd-Jones D, McDermott M, Meigs J, Moy C, Nichol G, O’Donnell CJ, Roger V, Rumsfeld J, Sorlie P, Steinberger J, Thom T, Wasserthiel-Smoller S, Hong Y, American Heart Association Statistics Committee and Stroke Statistics Subcommittee. Heart disease and stroke statistics-2007 update: a report from the American Heart Association Statistics Committee and Stroke Statistics Subcommittee. Circulation 2007;115:e69-e171.

2. Shaw LJ, Bairey Merz CN, Pepine CJ, Reis SE, Bittner V, Kelsey SF, Olson M, Johnson BD, Mankad S, Sharaf BL, Rogers WJ, Wessel TR, Arant CB, Pohost GM, Lerman A, Quyyumi AA, Sopko G, WISE Investigators. Insights from the NHLBI- Sponsored Women's Ischemia Syndrome Evaluation (WISE) Study: Part I: gender differences in traditional and novel risk factors, symptom evaluation, and gender- optimized diagnostic strategies. J Am Coll Cardiol 2006;47(Suppl. 3):S4-S20.

3. Bairey Merz CN, Shaw LJ, Reis SE, Bittner V, Kelsey SF, Olson M, Johnson BD, Pepine CJ, Mankad S, Sharaf BL, Rogers WJ, Pohost GM, Lerman A, Quyyumi AA, Sopko G, WISE Investigators. Insights from the NHLBI-Sponsored Women's Ischemia Syndrome Evaluation (WISE) Study: Part II: gender differences in presentation, diagnosis, and outcome with regard to gender-based pathophysiology of atherosclerosis and macrovascular and microvascular coronary disease. J Am Coll Cardiol 2006;47(Suppl. 3): S21-S29.

4. Heer T, Schiele R, Schneider S, Gitt AK, Wienbergen H, Gottwik M, Gieseler U, Voigtlander T, Hauptmann KE, Wagner S, Senges J. Gender differences in acute myocardial infarction in the era of reperfusion (the MITRA registry). Am J Cardiol 2002;89:511-517.

5. Lloyd-Jones DM, Larson MG, Beiser A, Levy D. Lifetime risk of developing coronary heart disease. Lancet 1999;353:89-92.

6. Tunstall-Pedoe H, Kuulasmaa K, Amouyel P, Arveiler D, Rajakangas AM, Pajak A. Myocardial infarction and coronary deaths in the World Health Organization. MONICA Project. Registration procedures, event rates, and case-fatality rates in 38 
populations from 21 countries in four continents. Circulation 1994; 90:583-612.

7. Vaccarino V, Parsons L, Every NR, Barron HV, Krumholz HM. Sexbased differences in early mortality after myocardial infarction. National Registry of Myocardial Infarction 2 participants. N Engl J Med 1999;341:217-225.

8. Vaccarino V, Abramson JL, Veledar E, Weintraub WS. Sex differences in hospital mortality after coronary artery bypass surgery: evidence for a higher mortality in younger women. Circulation 2002;105:1176-1181.

9. Hartz RS, Rao AV, Plomondon ME, Grover FL, Shroyer AL. Effects of race, with or without gender, on operative mortality after coronary artery bypass grafting: a study using the Society of Thoracic Surgeons national database. Ann Thorac Surg 2001;71:512-520.

10. Pepine CJ. Ischemic heart disease in women: facts and wishful thinking. J Am Coll Cardiol 2004;43:1727-1730.

11. Orshal JM, Khalil RA. Gender, sex hormones, and vascular tone. Am J Physiol Regul Integr Comp Physiol 2004;286:R23-R49.

12. Ricciardi MJ, Meyers S, Choi K, Pang JL, Goodreau L, Davidson CJ. Angiographically silent left main disease detected by intravascular ultrasound: a marker for future adverse cardiac events. Am Heart J 2003;146:507-512.

13. von Birgelen C, Hartmann M, Mintz GS, van Houwelingen KG, Deppermann N, Schmermund A, Bose D, Eggebrecht $H$, Neumann T, Gossl M, Wieneke H, Erbel R. Relationship between cardiovascular risk as predicted by established risk scores versus plaque progression as measured by serial intravascular ultrasound in left main coronary arteries. Circulation 2004;110: 1579-1585.

14. Nissen SE, Tuzcu EM, Libby P, Thompson PD, Ghali M, Garza D, Berman L, Shi H, Buebendorf E, Topol EJ, CAMELOT Investigators. Effect of antihypertensive agents on cardiovascular events in patients with coronary disease and normal blood pressure: the CAMELOT study: a randomized controlled trial. JAMA 2004;292: 2217-2225.

15. Nissen SE, Tuzcu EM, Schoenhagen P, Brown BG, Ganz P, Vogel RA, Crowe T, Howard G, Cooper C], Brodie B, Grines CL, DeMaria AN, REVERSAL Investigators. Effect of intensive compared with moderate lipid-lowering therapy on progression of coronary atherosclerosis: a randomized controlled trial. JAMA 2004;291:1071-1080.

16. Böse D, von Birgelen C, Erbel R. Intravascular ultrasound for the evaluation of therapies targeting coronary atherosclerosis. J Am Coll Cardiol 2007;49:925-932.

17. Lerman A, Zeiher AM. Endothelial function: cardiac events. Circulation 2005;111:363-368.

18. Bonetti PO, Lerman LO, Lerman A. Endothelial dysfunction: a marker of atherosclerotic risk. Arterioscler Thromb Vasc Biol 2003; 23:168-175.

19. Verma S, Buchanan MR, Anderson TJ. Endothelial function testing as a biomarker of vascular disease. Circulation 2003;108: 2054-2059.

20. von Mering GO, Arant CB, Wessel TR, McGorray SP, Bairey Merz CN, Sharaf BL, Smith KM, Olson MB, Johnson BD, Sopko G, Handberg E, Pepine CJ, Kerensky RA, National Heart Lung Blood Institute. Abnormal coronary vasomotion as a prognostic indicator of cardiovascular events in women: results from the National Heart, Lung, and Blood Institute sponsored Women's Ischemia Syndrome Evaluation (WISE). Circulation 2004;109:722-725.

21. Suwaidi JA, Hamasaki S, Higano ST, Nishimura RA, Holmes DR Jr, Lerman A. Long-term follow-up of patients with mild coronary artery disease and endothelial dysfunction. Circulation 2000;101: 948-954.

22. Hasdai D, Gibbons RJ, Holmes DR Jr, Higano ST, Lerman A. Coronary endothelial dysfunction in humans is associated with myocardial perfusion defects. Circulation 1997;96:3390-3395.

23. Al Suwaidi J, Higano ST, Holmes DR Jr, Rihal CS, Lerman A. Measuring maximal percent area stenosis poststent placement with intracoronary Doppler and the continuity equation and correlation with intracoronary ultrasound and angiography. Am J Cardiol 1999;84:650-654.

24. Bae JH, Rihal CS, Edwards BS, Kushwaha SS, Mathew V, Prasad A, Holmes DR Jr, Lerman A. Association of angiotensin-converting enzyme inhibitors and serum lipids with plaque regression in cardiac allograft vasculopathy. Transplantation 2006;82:1108-1111.

25. Mintz GS, Nissen SE, Anderson WD, Bailey SR, Erbel R, Fitzgerald PJ, Pinto FJ, Rosenfield K, Siegel RJ, Tuzcu EM, Yock PG. American college of cardiology clinical expert consensus document on standards for acquisition, measurement and reporting of intravascular ultrasound studies (ivus): A report of the American college of cardiology task force on clinical expert consensus documents developed in collaboration with the European society of cardiology endorsed by the society of cardiac angiograpy and interventions. J Am Coll Cardiol 2001;37:1478-1492.

26. Jones DW, Chambless LE, Folsom AR, Heiss G, Hutchinson RG, Sharrett AR, Szklo M, Taylor HA Jr. Risk factors for coronary heart disease in African Americans: the Atherosclerotic Risk in Communities Study, 1987-1997. Arch Intern Med 2002;162: 2565-2571.

27. Stenestrand U, Lindback J, Wallentin L, RIKS-HIA Registry. Longterm outcome of primary percutaneous coronary intervention vs prehospital and in-hospital thrombolysis for patients with ST-elevation myocardial infarction. JAMA 2006;14:1749-1756.

28. Heer T, Schiele R, Schneider S, Gitt AK, Wienbergen H, Gottwik M, Gieseler U, Voigtlander T, Hauptmann KE, Wagner S, Senges J. Gender differences in acute myocardial infarction in the era of reperfusion (the MITRA registry). Am J Cardiol 2002;89:511-517.

29. Lagerqvist B, Safstrom K, Stahle E, Wallentin L, Swahn E, FRISC II Study Group Investigators. Is early invasive treatment of unstable coronary artery disease equally effective for both women and men? J Am Coll Cardiol 2001;38:41-48.

30. Sadanandan S, Cannon CP, Gibson CM, Murphy SA, DiBattiste PM, Braunwald E, TIMI Study Group. A risk score to estimate the likelihood of coronary artery bypass surgery during the index hospitalization among patients with unstable angina and non-STsegment elevation myocardial infarction. J Am Coll Cardiol 2004; 44:799-803.

31. Qureshi MA, Safian RD, Grines CL, Goldstein JA, Westveer DC, Glazier S, Balasubramanian M, O'Neill WW. Simplified scoring system for predicting mortality after percutaneous coronary intervention. J Am Coll Cardiol 2003;42:1890-1895.

32. Nicholls SJ, Wolski K, Sipahi I, Schoenhagen P, Crowe T, Kapadia SR, Hazen SL, Tuzcu EM, Nissen SE. Rate of progression of coronary atherosclerotic plaque in women. J Am Coll Cardiol 2007;49:1546-1551.

33. Virmani R, Kolodgie FD, Burke AP, Farb A, Schwartz SM. Lessons from sudden coronary death: a comprehensive morphological classification scheme for athrosclerotic lesions. Arterioscler Thromb Vasc Biol 2000;20:1262-1275.

34. Perregaux D, Chaudhuri A, Mohanty P, Bukhari L, Wilson MF, Sung $\mathrm{BH}$, Dandona P. Effect of gender differences and estrogen 
replacement therapy on vascular reactivity. Metabolism 1999;48: 227-232.

35. Celermajer DS, Sorensen KE, Spiegelhalter DJ, Georgakopoulos D, Robinson J, Deanfield JE. Aging is associated with endothelial dysfunction in healthy men years before the age-related decline in women. J Am Coll Cardiol 1994;24:471-476.

36. Kern MJ, Bach RG, Mechem CJ, Caracciolo EA, Aguirre FV, Miller LW, Donohue TJ. Variations in normal coronary vasodilatory reserve stratified by artery, gender, heart transplantation and coronary artery disease. J Am Coll Cardiol 1996;28:1154-1160.

37. Britten MB, Zeiher AM, Schachinger V. Microvascular dysfunction in angiographically normal or mildly diseased coronary arteries predicts adverse cardiovascular long-term outcome. Coron Artery Dis 2004;15:259-264.

38. Marroquin OC, Kip KE, Mulukutla SR, Ridker PM, Pepine CJ, Tjandrawan T, Kelsey SF, Mankad S, Rogers WJ, Merz CN, Sopko G, Sharaf BL, Reis SE. Inflammation, endothelial cell activation, and coronary microvascular dysfunction in women with chest pain and no obstructive coronary artery disease. Am Heart J 2005;150:109-115.

39. Lerman A, Sopko G. Women and cardiovascular disease: clinical implications from the Women's Ischemia Syndrome Evaluation (WISE) study. Are we smarter? J Am Coll Cardiol 2006;47(Suppl. 3 ):S59-S62.

40. Buchthal SD, den Hollander JA, Merz CN, Rogers WJ, Pepine CJ, Reichek N, Sharaf BL, Reis S, Kelsey SF, Pohost GM. Abnormal myocardial phosphorus-31 nuclear magnetic resonance spectroscopy in women with chest pain but normal coronary angiograms. N Engl J Med 2000;342:829-835.

41. Johnson BD, Shaw LJ, Buchthal SD, Bairey Merz CN, Kim HW, Scott KN, Doyle M, Olson MB, Pepine CJ, den Hollander J, Sharaf B, Rogers WJ, Mankad S, Forder JR, Kelsey SF, Pohost GM National Institutes of Health-National Heart Lung Blood Institute. Prognosis in women with myocardial ischemia in the absence of obstructive coronary disease: results from the National Institutes of Health-National Heart, Lung, and Blood Institute-Sponsored Women's Ischemia Syndrome Evaluation (WISE). Circulation 2004;109:2993-2999.

42. Reis SE, Holubkov R, Conrad Smith AJ, Kelsey SF, Sharaf BL, Reichek N, Rogers WJ, Merz CN, Sopko G, Pepine CJ, WISE Investigators. Coronary microvascular dysfunction is highly prevalent in women with chest pain in the absence of coronary artery disease: results from the NHLBI WISE study. Am Heart J 2001;141:735-741.
43. Adams MR, Kaplan JR, Manuck SB, Koritnik DR, Parks JS, Wolfe MS, Clarkson TB. Inhibition of coronary artery atherosclerosis by 17-beta oestradiol in ovariectomized monkeys: lack of an effect of added progesterone. Atherosclerosis 1990;10: 1051-1057.

44. Wagner JD, Clarkson TB, St Clair RW, Schwenke DC, Shively CA, Adams MR. Estrogen and progesterone replacement therapy reduces low density lipoprotein accumulation in the coronary arteries of surgically postmenopausal cynomolgus monkeys. J Clin Invest 1991;88:1995-2002.

45. Kaplan JR, Manuck SB, Anthony MS, Clarkson TB. Premenopausal social status and hormone exposure predict postmenopausal atherosclerosis in female monkeys. Obstet Gynecol 2002;99: $381-388$.

46. Hayashi T, Fukuto JM, Ignarro I, Chadhun G. Basal release of nitric oxide from aortic rings is greater in female rabbits than in male rabbits: implications for atherosclerosis. Proc Natl Acad Sci USA 1992;89:11259-11263.

47. Collins P, Rosano GM, Sarrel PM, Ulrich L, Adamopoulos S, Beale CM, McNeill JG, Poole-Wilson PA. 17 beta-Oestradiol attenuates acetylcholine-induced coronary arterial constriction in women but not men with coronary heart disease. Circulation 1995;92:24-30.

48. Farhat MY, Lavigne MC, Ramwell PW. The vascular protective effects of estrogen. FASEB J 1996;10:615-624.

49. Ng MK, Quinn CM, McCrohon JA, Nakhla S, Jessup W, Handelsman DJ, Celermajer DS, Death AK. Androgens up-regulate atherosclerosis-related genes in macrophages from males but not females: molecular insights into gender differences in atherosclerosis. J Am Coll Cardiol 2003;42:1306-1313.

50. Hayward CS, Kelly RP, Collins P. The roles of gender, the menopause and hormone replacement on cardiovascular function. Cardiovasc Res 2000;46:28-49.

51. Mark D, Shaw L, Delong E, Califf RM, Pryor DB. Absence of sex bias in the referral of patients for cardiac catheterization. $N$ Engl J Med 1994;330:1101-1106.

52. Roeters van Lennep J, Borm J, Zwinerman A. No gender bias in the referral of patients for coronary angiography after myocardial perfusion scintigraphy with technetium-99 tetrofosmin. I Nud Cardiol 1999;6:596-604.

53. Sheldon WC. Indications for coronary arteriography. Heart Dis Stroke 1993;2:192-197. 